ORIGINAL RESEARCH

\title{
Effect of an educational rehabilitation program on prevention of falls after stroke
}

\author{
Esmat Sayed Abd-Almageed ${ }^{* 1}$, Asmaa Sayed Abd-Almageed ${ }^{1}$, Marwa Ali Almasry ${ }^{1}$, Heba Mohamed Fahmy ${ }^{1}$, Ghaydaa \\ A. Shehata ${ }^{2}$ \\ ${ }^{1}$ Faculty of Nursing, Assiut University, Egypt \\ ${ }^{2}$ Faculty of Medicine, Assiut University, Egypt
}

Received: May 14, 2020

Accepted: July 16, 2020

Online Published: July 24, 2020

DOI: $10.5430 /$ jnep.v10n11p31

URL: https://doi.org/10.5430/jnep.v10n11p31

\begin{abstract}
Objective: Fall is common in patient with stroke. The aim of the study was to evaluate the effect of an educational rehabilitation program on prevention of falls after stroke.

Methods: Quasi-experimental design was utilized. Setting: Neurology Department and Outpatient Clinics at Neurology, Psychiatry and Neurosurgery Hospital at Assiut University. Sample: Sixty adult patients diagnosed with stroke. Patients were equally divided into two equal groups (study and control) 30 patients each. Tools: Tool I-Patient assessment sheet. Tool II-Morse Fall Scale.

Results: A statistically significant improvement of circumstances and consequences of falls and decreasing the injuries due to fall $(p<.01)$ among the study group in comparison to the control group ones where, study group showed a decrease in the number of falling episodes ( $2.07 \pm 0.78$ vs. $5.4 \pm 1.73$ ), an improve in their ability to get up independent ( $83 \%$ vs. $23.3 \%$ ), no need for medical attention (3.3\% vs. $66.7 \%)$, and no restriction to their activities after falling $(0.0 \%$ vs. $56.7 \%)$.

Conclusions: The educational rehabilitation program had a statistically significant effect on the improvement of circumstances and consequences of falls and decreasing the injuries due to fall among the study group than among the control group. Recommendation: Simple illustrated educational booklets should be available for stroke patients. Replication of this study on a larger sample with extending the follow-up period to 6 months is suggested.
\end{abstract}

Key Words: Educational rehabilitation program, Falls, Stroke

\section{INTRODUCTION}

Stroke is a leading cause of adult disability and dependence in activities of daily living. It has a significant negative effect on the patients and their families. Stroke constitutes an important pathology, capable of increasing the chances of occurrence of falls due to the relevant physical impairment. Most people who survive a stroke have hemiplegia and remain in a position of postural asymmetry. This asymmetry and the difficulty of maintaining postural control impede orientation and stability to perform movements with the trunk and limbs and can cause fall. ${ }^{[1,2]}$

The high incidence of falls may be due to a combination of intrinsic and extrinsic risk factors. Intrinsic risk factors include slow and abnormal gait, decreased strength and balance, perceptual problems, visual deficits, cognitive impairment and impulsivity. All of these factors make them inherently vul-

\footnotetext{
* Correspondence: Esmat Sayed Abd-Almageed; Email: dr_es_sa@yahoo.com; Address: Medical-Surgical Nursing, Faculty of Nursing, Assiut University, Egypt.
} 
nerable to fall. Extrinsic risk factors for falling are related to the behavior and activities of persons in the environment in which they live. Also, drugs such as sedatives and antidepressants, which are commonly used after stroke, may increase the risk of fall. ${ }^{[3,4]}$

Falling is common after stroke, it is occurring in the acute, rehabilitative, and chronic phases after stroke. Falls may lead to death or serious injury, minor injuries, hip fracture, functional limitations, decreased mobility and activity, and fear of falling, which is a significant psychological consequence of falls. These can have implications for independence after stroke. Falls increase the hospitalization period and treatment cost, besides causing physical and psychological discomforts. All these findings make falling and its prevention is important for stroke patient. ${ }^{[5,6]}$

The risk of both stroke and falls increase with age. In addition, falls are common after stroke and between 14\%-65\% of stroke patients suffering fall while in hospital and up to $73 \%$ of stroke patients suffering a fall in the first 6 months after return home. Falls in the stroke patients may result in serious injury, with the rate of fracture up to 4-time higher than in general population. So, prevention of fall is of vital importance for stroke patients, their families, and society. ${ }^{[7,8]}$

Most of the complications observed in stroke survivors considerably increase the risk of falls for these patients. Nurses perform a central role in stroke rehabilitation. It emphasizes that providing support to patients and caregivers is an important element of caring for people who have experienced a stroke. For this reason, nurses should be actively involved in patient safety and fall-prevention awareness and interventions. ${ }^{[9]}$

Although fall prevention presents a multi-professional approach, nurses play an important role in outcomes in fall prevention, as they have close and continuous contact with the patients in the day-to-day nursing care they provide in comparison to other health professionals. Detecting patients at high risk for falling is an important nursing assessment, so that implementation of individualized interventions for each patient according to the risk factors presented. Patients and families should understand the fall risks and how to prevent these risks. If learning needs have been identified, nurse should teach them to address knowledge gaps. Patients and their significant others need to understand the potential consequences of not following the recommendations as well as feasible alternatives and possible outcomes. ${ }^{[10,11]}$

\subsection{Significance}

In Assiut Governorate the prevalence of stroke is high, with a population of about 3.5 million inhabitants, crude prevalence is $9.63 / 1,000$ population. ${ }^{[12]}$ According to Neurological and Psychiatric Assiut University Hospital records (2018) about 903 female patients and 927 male patients were admitted with stroke. Falls can lead to serious consequences such as fractures or even death, in addition to the financial burden. Considering all these facts; this study was conducted to find out the effect of an educational rehabilitation program on prevention of falls after stroke. Hopefully this program contributes to maintain safety of stroke patient and guide nurses to take in their account the important of equipping the patients with the necessary information to help them return to previous state of independency and safety.

\subsection{Aim of the study}

The aim of this study was to evaluate the effect of an educational rehabilitation program on prevention of falls after stroke.

\subsection{Research hypotheses}

To fulfil the aim of this study, the following research hypothesis formulated: After applying the educational rehabilitation program, incidence of falls episodes and injuries due to falls will be lesser in the study group than in the control group.

\subsection{Operational definition}

Fall: It is considered an event that results in a person coming to rest involuntarily on the ground or floor or other lower level, with or without injuries. ${ }^{[13]}$

\section{MATERial AND Method}

\subsection{Research design}

Quasi-experimental design was utilized in this study, which is used to estimate causal effects of an intervention on target population, with the lack of randomization. ${ }^{[14]}$

\subsection{Setting}

The study was conducted in the Neurology Department and Outpatient Clinics at Neurology, Psychiatry and Neurosurgery Hospital at Assiut University.

\subsection{Sample}

A sample of 60 adult stroke patients, their age ranged from 18 to 65 , and both male and female were included in this study. Patients divided equally on random basis into two equal groups (study and control) 30 patients each. The study group received the educational rehabilitation program while the control group received the routine hospital care during the time of discharge.

\subsection{Exclusion criteria}

-History of trauma or joint replacement (pre or post stoke). -Parkinson's disease. 
-Complete hemiplegia.

-Had a medical condition precluding exercise such as unstable cardiovascular disease.

\subsection{Tools}

Two tools were utilized for data collection:

Tool (1): Patient assessment sheet: This sheet developed by the researchers based on literature review, it consisted of five parts:

Part I: Demographic data: Age, sex, marital status, occupation, educational level, and residence.

Part II: Medical data: Patient's diagnosis, affected paralytic side, and length of hospital stay.

Part III: Risk factors for falling: The multiple factors which may have contributed to the fall. They included intrinsic (physiological attributes of the individual as impaired vision, impaired mobility, neuropathy, orthostatic hypotension, confusion) and extrinsic (environmental factors as medications, ambulatory aids, fear of falling, environmental hazards, nutrition, medical conditions).

Part IV: Circumstances and consequences of falls: Number of falling episodes, activities during falling, direction of fall, location, ability to get up independence, length of lie, medical attention, and restricted activity.

Part V: Classification of injuries due to falls: Nil (no injuries recorded), minor injuries (laceration that did not require suturing), moderate injuries (laceration that required suturing, head injury required neurological observations, damage to dentures, or soft tissue injury required radiological investigations), and severe injuries (fracture).

Tool (2): Morse Fall Scale (MFS): It was developed by Morse et al. (1989) ${ }^{[15]}$ to identify fall-prone patients. It is the first instrument to be directed to the elaboration of a care plan based on specific nursing interventions, aimed at overcoming the risk of falling. It was adopted by the researchers to assess patient's likelihood of falling.

\subsection{Scoring system}

MFS consists of six variables that are quick and easy to score (history of falling, secondary diagnosis, ambulatory aid, intravenous therapy/heparin lock, gait, and mental status). To obtain the Morse Fall score add the score from each category, the score is then tallied and recorded on the patient's chart. Risk level and recommended actions are then identified.

$-<25$ : Low risk.

- 25-45: Moderate risk.

- > 45: High risk.

Published by Sciedu Press

\subsection{Ethical consideration}

Permission to carry out the study was obtained from the ethical committee of the faculty of nursing and from the hospital authorities of Neurology Department and Outpatient Clinics of Neurology at Neurological and Psychiatric Assiut University Hospital. Before the initial interview, the researchers introduced themselves to the patients. Oral agreement for voluntary participation was obtained. Anonymity and confidentiality were assured through coding of the data. Patients had the right to refuse participation in the study and at any time they can withdraw.

\subsection{Content validity}

It established by a panel of five experts (included 3 from Medical Surgical Nursing staff and two from the Neurology staff) who reviewed the tools for clarity, comprehensiveness, understanding, and applicability. Minor modifications were required. Reliability of MFS was ascertained with Cronbach's alpha $=0.96$

\subsection{Pilot study}

It was implemented on $10 \%$ of the study sample, to ensure clarity and feasibility of the tools, and identify any difficulties needed to be handled. Minor changes were done to the tools, so the sample of the pilot study was excluded from the actual study sample.

\subsection{The rehabilitation program}

It was developed by the researchers through review literature and research results about falls prevention after stroke. An educational booklet prepared and divided into three parts; The first part under the title of "Introduction" included information about the fall in the subtitles of "What is fall?", "What are the intrinsic and extrinsic risk factors of falls?". The second part under the title of "Preventive measures" included information about preventive measures to decrease the risk of falls in the subtitles of "Promotion of a better vision", "Promotion of vitamin D", "Guidance on drug interactions which can cause dizziness, syncope, and malaise", "Steps of using crutches and walkers", "Guidance on increased safety attention in home through environmental adaptation and modifications, including handrails for stairs, grab rails for bathroom, good lighting, and slip-resistant surfacing for outside areas. ". The third part in under the title of "Exercises" included information about physical exercises that strength body muscles and maintain equilibrium, and exercises to strength muscles of the lower limbs,. Experts in the field of nursing and neurology checked the content for completeness, clarity, and applicability and modifications were done accordingly. 


\subsection{Procedure}

The present study proceeded using the following phases:

\section{Assessment phase:}

The researchers met the selected patients from inpatients; each patient from both groups (study and control) informed with the purpose and nature of the study. Base line data collected using tool 1 part (I, II, and III) and tool 2.

\section{Implementation phase:}

- The study group was given the educational rehabilitation program by the researchers.

- Program content was covered over three sessions; each session took about $30 \mathrm{~min}$. The study was conducted in the morning and afternoon shifts. The program was given on an individual basis. During the session one of the family members was present to ensure patient support and take care of their patients during application of the program at home.

- The first session covered the information included in the first portion of the educational booklet (Introduction).

- The second session covered the second portion of the educational booklet (Preventive measures).

- The third session covered the third portion of the educational booklet (Exercises).

- At the end of each session feedback was received from the patients to assess their understanding, and then the researchers explained any difficult points.

- During the session each patient was given a copy of the booklet in clear Arabic language, to help them retain the learned material.

- The program was carried out throughout a period of 4 months for the study group only while the control group received the routine hospital care during the time of discharge which included given the patients a follow-up card by a member of the nursing team for follow up in outpatient clinics every two weeks and give them a list of prescribed medications to take during the recovery period.

- The researchers arranged with the patients of both groups (study and control) the time and place for follow up which were after 4 months in the Outpatient Clinics at Neurology, Psychiatry and Neurosurgery Hospital at Assiut University.

- The researchers ensured commitment of the study group patients to implement the program every 2 weeks by telephone and also, to assess circumstances and consequences of falls and injuries due to falls.

- Data collected through the period from the beginning of September 2018 to the end of October 2019.

\section{Evaluation phase:}

Patients reassessed after 4 months using tool (1) part IV and V. Both study and control group patients attended the follow-up sessions to evaluate the effect of the rehabilitation program. The session took about 20 minutes.

\subsection{Statistical analysis}

Data were tested for normality using the Anderson-Darling test and for homogeneity variances. Categorical variables were described by number and percent (N, \%), where continuous variables described by mean and standard deviation (Mean, SD). Chi-square test and fisher exact test used to compare between categorical variables, $t$-test and ANOVA TEST were used to compare between continuous variables. A two-tailed $p<.05$ was considered statistically significant. Person Correlation was used to appear the association between scores. Data analysis was performed with IBM SPSS 20.0 software.

\section{ReSults}

Table 1 shows that the highest percent of the studied patients their ages more than 50 years, with a mean age $(51.33 \pm$ 12.31). The highest percentages of them were male, married, not educated, and from rural area $(61.7 \%, 85 \%, 56.7 \%$, and $68.3 \%$ ) respectively. No statistically significant difference was found between both study and control groups regarding the demographic characteristics.

Table 2 reveals that the highest percent in both study and control groups had ischemic stroke $(76.7 \%)$. Also, the right side was the common affected paralytic side in both groups $(53.3 \%)$. No statistically significant difference was found between the two groups regarding the medical data.

Table 3 clarifies that the most common intrinsic risk factors for falling in both study and control groups were impaired mobility, unstable gait, and poor balance $(73.3 \%)$ followed by impaired vision (61.7\%). While regarding extrinsic risk factors, medical condition was the most common (95\%) followed by poly pharmacy $<5$ medications $(85 \%)$. No statistically significant difference was found between the two groups regarding risk factors for falling.

Table 4 illustrates that both study and control group patients were at risk for falling, where more than one third of them were at moderate risk for falling and the last were at low and high risk of falling. No statistically significant difference was found between the study and the control groups regarding the risk of falling according to MFS.

Table 5 reflects that there was a statistically significant improvement in circumstances and consequences of falls among the study group in comparison to the control group during 
the follow up period. Where, the study group showed a de- or no restriction to their activities after falling $(p<.01)$. Falls crease in the number of falling episodes, improving in their occurred most frequently in both groups indoor, towered the ability to get up independent, no need for medical attention, weaker side, while walking or transferring.

Table 1. Frequency distribution of demographic characteristics of the studied sample

\begin{tabular}{|c|c|c|c|c|c|c|c|}
\hline \multirow{2}{*}{ Characteristics } & \multicolumn{2}{|c|}{ Study $(n=30)$} & \multicolumn{2}{|c|}{ Control $(n=30)$} & \multicolumn{2}{|c|}{ Total $(n=60)$} & \multirow{2}{*}{$p$ value } \\
\hline & N. & $\%$ & N. & $\%$ & N. & $\%$ & \\
\hline \multicolumn{8}{|l|}{ Age } \\
\hline $20-<55$ years & 8 & 26.7 & 14 & 46.7 & 22 & 36.7 & $.180^{\mathrm{NS}}$ \\
\hline$\geqslant 55$ years & 22 & 73.3 & 16 & 53.3 & 38 & 63.3 & \\
\hline Mean \pm SD & \multicolumn{2}{|c|}{$53.93 \pm 10.83$} & \multicolumn{2}{|c|}{$48.73 \pm 13.31$} & \multicolumn{2}{|c|}{$51.33 \pm 12.31$} & .102 \\
\hline \multicolumn{8}{|l|}{ Gender } \\
\hline Male & 21 & 70.0 & 16 & 53.3 & 37 & 61.7 & $.184^{\mathrm{NS}}$ \\
\hline Female & 9 & 30.0 & 14 & 46.7 & 23 & 38.3 & \\
\hline \multicolumn{8}{|l|}{ Marital status } \\
\hline Single & 1 & 3.3 & 5 & 16.7 & 6 & 10.0 & \\
\hline Married & 29 & 96.7 & 22 & 73.3 & 51 & 85.0 & $.085^{\mathrm{NS}}$ \\
\hline Divorced & 0 & 0.0 & 1 & 3.3 & 1 & 1.7 & \\
\hline Widowed & 0 & 0.0 & 2 & 6.7 & 2 & 3.3 & \\
\hline \multicolumn{8}{|l|}{ Educational level } \\
\hline High education & 2 & 6.7 & 3 & 10.0 & 5 & 8.3 & \\
\hline Secondary education & 5 & 16.7 & 8 & 26.7 & 13 & 21.7 & $.138^{\mathrm{NS}}$ \\
\hline Read and write & 7 & 23.3 & 1 & 3.3 & 8 & 13.3 & \\
\hline Not educated & 16 & 53.3 & 18 & 60.0 & 34 & 56.7 & \\
\hline \multicolumn{8}{|l|}{ Occupation } \\
\hline Employee & 2 & 6.7 & 3 & 10.0 & 5 & 8.3 & \\
\hline Farmer & 9 & 30.0 & 2 & 6.7 & 11 & 18.3 & \\
\hline Housewife & 9 & 30.0 & 13 & 43.3 & 22 & 36.7 & $.076^{\mathrm{NS}}$ \\
\hline Not work & 7 & 23.3 & 4 & 13.3 & 11 & 18.3 & \\
\hline Skilled worker & 3 & 10.0 & 8 & 26.7 & 11 & 18.3 & \\
\hline \multicolumn{8}{|l|}{ Residence } \\
\hline Rural & 23 & 76.7 & 18 & 60.0 & 41 & 68.3 & $.165^{\mathrm{NS}}$ \\
\hline Urban & 7 & 23.3 & 12 & 40.0 & 19 & 31.7 & \\
\hline
\end{tabular}

Note. Chi-square test; Independent t-test; NS: Not Significant $p>.05$.

Table 2. Frequency distribution of medical data of the studied sample

\begin{tabular}{|c|c|c|c|c|c|c|c|}
\hline \multirow{2}{*}{ Variable } & \multicolumn{2}{|c|}{ Study $(n=30)$} & \multicolumn{2}{|c|}{ Control $(n=30)$} & \multicolumn{2}{|c|}{ Total $(n=60)$} & \multirow{2}{*}{$p$ value } \\
\hline & N. & $\%$ & N. & $\%$ & N. & $\%$ & \\
\hline \multicolumn{8}{|l|}{ Patient's diagnosis } \\
\hline Hemorrhagic stroke & 8 & 26.7 & 6 & 20.0 & 14 & 23.3 & $.760^{\mathrm{NS}}$ \\
\hline Ischemic stoke & 22 & 73.3 & 24 & 80.0 & 46 & 76.7 & \\
\hline \multicolumn{8}{|c|}{ Affected paralytic side } \\
\hline Right & 18 & 60.0 & 14 & 46.7 & 32 & 53.3 & $.400^{\mathrm{NS}}$ \\
\hline Left & 12 & 40.0 & 15 & 50.0 & 27 & 45.0 & \\
\hline Bilateral & 0 & 0.0 & 1 & 3.3 & 1 & 1.7 & \\
\hline \multicolumn{8}{|c|}{ Length of hospital stay } \\
\hline from 2-5 days & 23 & 76.7 & 16 & 53.3 & 39 & 65.0 & $.102^{\mathrm{NS}}$ \\
\hline 6-10 days & 7 & 23.3 & 12 & 40.0 & 19 & 31.7 & \\
\hline More than 10 days & 0 & 0.0 & 2 & 6.7 & 2 & 3.3 & \\
\hline
\end{tabular}

Note. Chi-square test; NS: Not Significant $p>.05$ 
Table 3. Intrinsic and extrinsic risk factors for falling among study and control groups

\begin{tabular}{|c|c|c|c|c|c|c|c|}
\hline \multirow{2}{*}{ Risk factors } & \multicolumn{2}{|c|}{ Study $(n=30)$} & \multicolumn{2}{|c|}{ Control $(n=30)$} & \multicolumn{2}{|c|}{ Total } & \multirow{2}{*}{$p$ value } \\
\hline & N. & $\%$ & N. & $\%$ & N. & $\%$ & \\
\hline \multicolumn{8}{|l|}{ A-Intrinsic factors: } \\
\hline Impaired vision & 16 & 53.3 & 21 & 70.0 & 37 & 61.7 & $.184^{\mathrm{NS}}$ \\
\hline Impaired mobility, unstable gait, and poor balance & 28 & 93.3 & 16 & 53.3 & 44 & 73.3 & $<.001^{* *}$ \\
\hline Lower extremity sensory neuropathy & 3 & 10.0 & 7 & 23.3 & 10 & 16.7 & $.166^{\mathrm{NS}}$ \\
\hline Orthostatic hypotension & 2 & 6.7 & 5 & 16.7 & 7 & 11.7 & $.228^{\mathrm{NS}}$ \\
\hline Confusion & 8 & 26.7 & 11 & 36.7 & 19 & 31.7 & $.405^{\mathrm{NS}}$ \\
\hline \multicolumn{8}{|l|}{ B-Extrinsic factors: } \\
\hline Medications (poly-pharmacy > 5 medications) & 24 & 80.0 & 27 & 90.0 & 51 & 85.0 & $.278^{\mathrm{NS}}$ \\
\hline Ambulatory aids such as canes and walkers & 19 & 63.3 & 14 & 46.7 & 33 & 55.0 & $.194^{\mathrm{NS}}$ \\
\hline Fear of falling & 9 & 30.0 & 9 & 30.0 & 18 & 30.0 & $1.000^{\mathrm{NS}}$ \\
\hline $\begin{array}{l}\text { Environmental hazards: poor lighting. clutter, a slippery floor } \\
\text { and an uneven threshold }\end{array}$ & 12 & 40.0 & 11 & 36.7 & 23 & 38.3 & $.791^{\mathrm{NS}}$ \\
\hline Nutrition & 2 & 6.7 & 2 & 6.7 & 4 & 6.6 & $1.000^{\mathrm{NS}}$ \\
\hline $\begin{array}{l}\text { Medical conditions: (diabetes mellitus, arthritis, urinary } \\
\text { incontinence, osteoporosis) }\end{array}$ & 28 & 93.3 & 29 & 96.7 & 57 & 95.0 & $.554^{\mathrm{NS}}$ \\
\hline
\end{tabular}

Table 4. Comparison between study and control groups according to Morse Fall Scale

\begin{tabular}{|c|c|c|c|c|c|c|c|}
\hline \multirow{2}{*}{ Category } & \multicolumn{2}{|c|}{ Study $(\mathrm{n}=\mathbf{3 0})$} & \multicolumn{2}{|c|}{ Control $(n=30)$} & \multicolumn{2}{|c|}{ Total } & \multirow{2}{*}{$p$ value } \\
\hline & N. & $\%$ & N. & $\%$ & N. & $\%$ & \\
\hline Low risk & 11 & 36.7 & 6 & 20.0 & 17 & 28.3 & \\
\hline Moderate risk & 10 & 33.3 & 16 & 53.3 & 26 & 43.3 & $.233^{\mathrm{NS}}$ \\
\hline High risk & 9 & 30.0 & 8 & 26.7 & 17 & 28.3 & \\
\hline
\end{tabular}

Note. Chi-square test; NS: Not Significant $p>.05$.

Table 5. Comparison between study and control groups as regard circumstances and consequences of falls through 4 months follow-up interval

\begin{tabular}{|c|c|c|c|c|c|}
\hline \multirow{2}{*}{ Variable } & \multicolumn{2}{|c|}{ Study $(n=30)$} & \multicolumn{2}{|c|}{ Control $(n=30)$} & \multirow{2}{*}{$p$ value } \\
\hline & N. & $\%$ & N. & $\%$ & \\
\hline \multicolumn{6}{|l|}{ Number } \\
\hline 1-3 episodes & 30 & 100.0 & 0 & 0.0 & $<.001^{* *}$ \\
\hline 4-5 episodes & 0 & 0.0 & 22 & 73.3 & \\
\hline More than 5 episodes & 0 & 0.0 & 8 & 26.7 & \\
\hline Mean \pm SD & \multicolumn{2}{|c|}{$2.07 \pm 0.78$} & \multicolumn{2}{|c|}{$5.4 \pm 1.73$} & $<.001^{* *}$ \\
\hline \multicolumn{6}{|l|}{ Activity } \\
\hline Walking & 11 & 36.7 & 18 & 60.0 & $.367^{\mathrm{NS}}$ \\
\hline Transfers & 13 & 43.3 & 10 & 33.3 & \\
\hline Turning & 2 & 6.7 & 0 & 0.0 & \\
\hline Bending & 2 & 6.7 & 1 & 3.3 & \\
\hline Carrying/lifting & 1 & 3.3 & 0 & 0.0 & \\
\hline Other & 1 & 3.3 & 1 & 3.3 & \\
\hline \multicolumn{6}{|l|}{ Direction of fall } \\
\hline Weaker side & 14 & 46.7 & 15 & 50.0 & $.212^{\mathrm{NS}}$ \\
\hline Forwards & 13 & 43.3 & 7 & 23.3 & \\
\hline Backwards & 2 & 6.7 & 2 & 6.7 & \\
\hline Stronger side & 1 & 3.3 & 3 & 10.0 & \\
\hline Unknown & 0 & 0.0 & 3 & 10.0 & \\
\hline \multicolumn{6}{|l|}{ Location } \\
\hline a. Indoor & 24 & 80.0 & 24 & 80.0 & $1.000^{\mathrm{NS}}$ \\
\hline b. Outdoor & 6 & 20.0 & 6 & 20.0 & \\
\hline Able to get up independence & 25 & 83.3 & 7 & 23.3 & $<.01^{* *}$ \\
\hline \multicolumn{6}{|l|}{ Length of lie } \\
\hline$<5$ Min & 10 & 33.3 & 12 & 40.0 & $.438^{\mathrm{NS}}$ \\
\hline 5-30 Min & 19 & 63.3 & 15 & 50.0 & \\
\hline 30 Min & 1 & 3.3 & 3 & 10.0 & \\
\hline Medical attention & 1 & 3.3 & 20 & 66.7 & $<.01^{* *}$ \\
\hline Restricted activity & 0 & 0.0 & 17 & 56.7 & $<.01^{* *}$ \\
\hline
\end{tabular}


Figure 1 reflects that a statistically significant decrease in the injuries due to fall was found among the study group than among the control group during the follow up period, where $56.7 \%$ of the study group had no injuries and the last
$43.3 \%$ had only minor injuries. While $33.3 \%$ and $50 \%$ of the control group had sever and moderate injuries consequently, and only $16.7 \%$ had no injuries $(p<.01)$.

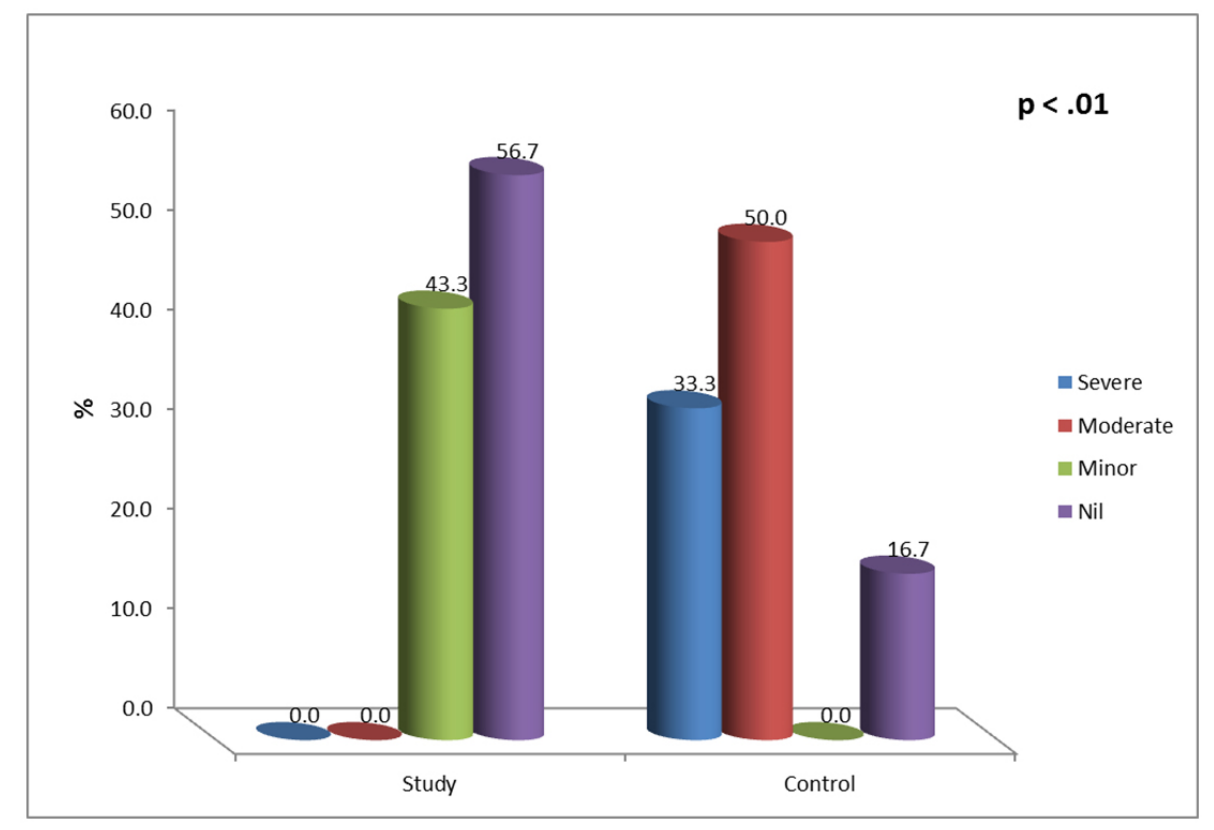

Figure 1. Classification of injuries due to fall among study and control group patients

Table 6 shows that a positive correlation was found between the classification of injuries due to falls and age group in both study and control groups, which means that the severity of injuries due to fall in stroke patients increased in old age than in young age. Regarding gender no correlation was found in both groups.

Table 6. Correlation between age group and gender of the studied sample with classification of injuries due to falls

\begin{tabular}{llllll}
\hline \multirow{2}{*}{ Items } & \multicolumn{2}{l}{ Classification of injuries due to falls } \\
\cline { 2 - 3 } & \multicolumn{2}{l}{ Study group $(\mathbf{n}=\mathbf{3 0})$} & & \multicolumn{2}{l}{ Control group $(\mathbf{n}=\mathbf{3 0})$} \\
\cline { 2 - 3 } \cline { 5 - 6 } & $\boldsymbol{R}$ & $\boldsymbol{p}$ & & $\boldsymbol{R}$ & $\boldsymbol{p}$ \\
\hline Age & $.375^{*}$ & .041 & & 0.160 & .056 \\
Gender & 0.308 & .097 & & 0.200 & .288 \\
\hline
\end{tabular}

*Significant $p<.05$.

\section{Discussion}

Fall is common in patient with stroke. The risk of injuries due to fall might be increased after hospitalization. Individuals with stroke have an increased risk for fractures. Also, fear of fall is a common consequence of falls that may decrease physical activity and loss of independence. So, it is important to evaluate falls risk and necessary strategies should be implemented to minimize falls before hospital discharge. ${ }^{[16,17]}$

Published by Sciedu Press
Regarding demographic data, this study showed that the largest percent of both study and control groups their ages were more than 50 years, male, married, and not educated. This result agreed with Mohsen et al. (2017) ${ }^{[18]}$ who found that the majority of stroke patients were over the age of 50 years, male, married, and more than one-third of them were illiterate.

Regarding medical data the current study found that the highest percent in both study and control groups had ischemic stroke. Khedr et al. (2013) ${ }^{[12]}$ were in the same line with the current study, they found a higher prevalence of ischemic stroke than hemorrhagic stroke.

As regard risk factors for fall, the current study revealed that the most common intrinsic risk factors for falling in both groups were impaired mobility, unstable gait, and poor balance followed by impaired vision. These can be attributed to hemiplegia or paresis of the lower limbs result from stroke. Which, affect the gait of the patients, their ability to balance, and impair safe walking that lead to fall. On the other hand, medical condition was the most common extrinsic risk factor followed by poly pharmacy $<5$ medications. Also, according to MFS scores both study and control group patients were at risk for fall where, more than one third of them were at moderate risk for fall and the last were at low and high risk 
for fall.

Congruent with the current study results Goh et al. (2016) ${ }^{[19]}$ suggested that stroke is associated with increased frequency of falls or increased risk of falls recurrent. Also, Said et al. $(2016)^{[20]}$ concluded that failure to adequately address risk factors for falls during hospitalization could contribute to falls post-discharge. Also, Czernuszenko \& Czonkowska $(2009)^{[21]}$ added that disturbed balance, dependence in daily activities, depression, and multitasking (such as speaking while walking) were the common risk factors for falling in stroke patients after hospital discharge.

In this regard Tsur and Segal (2010) ${ }^{[22]}$ reported that the identification of patients susceptible to falls and risk factors are essential as these would be the focus of intervention measures. Also, Callis (2016) ${ }^{[23]}$ found that the main risk factor associated with fall was using drugs such as antihyperglycemic, antidepressants, antihypertensive, or sedatives on the day of the fall occurrence, they added that visual and communication disorders are other risk factors to take into account.

Regarding the effect of the rehabilitation program, the present study proved that after applying the rehabilitation program there was a statistically significant improvement in circumstances and consequences of falls among the study group in comparison to the control group ones, where the study group showed a decrease in the number of falling episodes, an improve in their ability to get up independent, no need for medical attention, and no restriction to their activities after fall.

From the researchers' point of view this may be due to containment of the rehabilitation program with the needed instructions and preventive measures that helped in improve circumstances and consequences of falls such as, collaborating with the patients to determine the best ways to minimize risk factors, adaptation of the environment in which patients live to become safe and comfortable (e.g., improving lighting, rearranging furniture, and wiping wet areas on floors), and demonstration the right ways to use crutches and walkers. Moreover, continuous follow up of study group patients by the researchers to confirm adherence to the program.

This result agreed with Hanger et al. (2014) ${ }^{[24]}$ who found four types of falls in patients with stroke, as a result, they recommended that rehabilitation programs should be designed to prevent falls and patients and families should be educated regarding prevention of ambulation in society, prescription of auxiliary devices, and modification of home environment. Also, Moncada and Mire (2017) ${ }^{[25]}$ added that home modification and training patients who have a high risk of falls about proper use of assistive devices are important for improving safety and effective in reducing falls.

Kulcu (2015) ${ }^{[26]}$ supported the current study results; they stated that nurses as part of the multidisciplinary team, implement fall prevention interventions to prevent future falls. Therefore, it is up to nursing to detect individual risk factors, to elaborate and evaluate measures to prevent falls; including; education of patients and their families, environmental modifications, ambulatory aids, exercises, medication review, and hip protectors.

Similarly, Cavalcante et al. $(2018)^{[27]}$ mentioned that it is important to the nurse to develop preventive actions focused on the orientation, education, and empowerment of patients and their relatives about stroke, explaining risks and consequences of falls, in order to mobilize the patient and the family to take due care to reduce the incidence of falls. Besides, Alves (2017) ${ }^{[11]}$ recommended that nurses must understand the risk factors and their real responsibilities for falls prevention.

In the current study falls occurred most frequently in both study and control groups indoor, while walking or transferring, and towered the weaker side which can be attributed to loss of bone mineral density on their paretic side, become fragile, and have an increased risk of fall. Also, a statistically significant decrease in the injuries due to fall was found among the study group than among the control group.

This could explain that teaching the study group patients about preventive measures resulted in decrease in the injuries due to fall, such as use of vitamin D, calcium supplements and hip protectors. Physical exercises that strength muscles. Measures to prevent fall at night, such as adequate lighting, and consideration of a commode in the bedroom. Furthermore, measures to prevent falls in the morning where, activities such as showering, dressing and transfers all tend to occur in the morning at a time when people may still have residual effects from sedative drugs, difficulties with morning stiffness and problems with postural-hypotension.

The current study results coincided with Goto et al. (2019) ${ }^{[28]}$ who explained that the mutual picture associated with falls was one of losing balance while indoors and going toilet. Also, Schmid et al. (2013) ${ }^{[29]}$ evaluated circumstances and consequences of falls in stroke patients, their study showed that the majority of falls occurred indoors, during an activity of daily living such as toileting, while walking or using a ladder, falling out of a chair, and forgetting to use an assistive device.

In the same line Tsur and Segal $(2010)^{[22]}$ recommended that rehabilitation programs included fall prevention strategies 
should be developed. Schneider (2017) ${ }^{[30]}$ added that nurses need to be aware of ongoing research regarding vitamin D and provide information about this important vitamin for stroke patients. Also, Resnick et al. (2020) ${ }^{[31]}$ concluded that engagement of patients in moderate level physical activity was found to be slightly protective from falling.

Verheyden et al. (2013) ${ }^{[2]}$ disagreed with the current results; they conducted a systematic review and found a little evidence about the benefit of interventions for fall prevention in patients after stroke so, more research in this important area is therefore warranted. Additionally, Dean et al. (2011) ${ }^{[32]}$ concluded that lower limb exercise classes improved walking capacity and speed in stroke patient, but there was no effect on prevention of fall.

Finally, the current study revealed that a positive correlation was found between the severity of injuries due to falls and age group in both study and control groups. This may explained by, as with aging stroke patients both have high risks of fall toward the paresis side and have high degrees of osteoporosis on the same side, and osteoporosis increased by aging, so increasing risk of fall-related injuries. Similarly, Divani et al. (2009) ${ }^{[33]}$ found that injuries due to fall in stroke patients were associated with higher age.

\section{Conclusion}

The educational rehabilitation program had a statistically significant effect on the improvement of circumstances and consequences of falls after stroke and decreasing the injuries due to fall among the study group in comparison to the control group ones, where the study group showed a decrease in the number of falling episodes, an improve in their ability to get up independent, no need for medical attention, or no restriction to their activities after falling.

\section{Recommendations}

- Educational rehabilitation program could potentially be incorporated into the usual hospital care.

- Establishment of educational centers in urology departments to educate stroke patients about fall prevention using simple illustrated educational booklets, pamphlets, videotapes, and models, especially for patients who are not educated.

- Replication of this study on a larger sample and in different geographical areas in Egypt with extending the follow-up period to 6 months is suggested to provide more comprehensive information about the effect of the rehabilitation program on the prevention of fall.

\section{CONFlicts of InTEREST Disclosure}

The authors declare that there is no conflict of interest.

\section{REFERENCES}

[1] Jeong H, Han SJ, Jang SJ, et al. Factors Affecting Activities of Daily Living in Severely Disabled Stroke Patients. Brain Neurorehabil. 2018 Sep; 11(2):e11. https://doi.org/10.12786/bn.2018.1 1.e11

[2] Verheyden GS, Weerdesteyn V, Pickering RM, et al. Interventions for preventing falls in people after stroke. Cochrane Database of Systematic Reviews. 2013. PMid:23728680 https : //doi .org/10 .1002/14651858. CD008728.pub2

[3] Huang Y, Zhang L, Luo T, et al. Effectiveness of A Fall Prevention Protocol for Patients with Ischemic Stroke During Hospitalization. Int J Neurol Neurother. 2016; 3: 063. https ://doi .org/10.239 $37 / 2378-3001 / 3 / 6 / 1063$

[4] Bor A, Matuz M, Csatordai M, et al. Medication use and risk of falls among nursing home residents: a retrospective cohort study. Int J Clin Pharm. 2017; 39(2): 408-415. PMid:28188510 https://doi.org/10.1007/s11096-017-0426-6

[5] Goh HT, Nadarajah M, Hamzah NB, et al. Falls and Fear of Falling After Stroke: A Case-Control Study. PM\&R. 2016; 8: 1173-1180. PMid:27268565 https://doi.org/10.1016/j.pmrj . 2016.05 .012

[6] Kim K, Jung HK, Kim CO, et al. Evidence-based guidelines for fall prevention in Korea. Korean J Intern Med. 2017; 32: 199-210. PMid:28049285 https://doi.org/10.3904/kjim.2016.218

Published by Sciedu Press
[7] Batchelor F, Hill K, Mackintosh S, et al. What Works in Falls Prevention After Stroke? A Systematic Review and Meta-Analysis. Stroke. 2010; 41: 1715-1722. PMid:20616328 https://doi.org/10.116 1/STROKEAHA. 109.570390

[8] Mun K, Pin M.: Stroke and Falls-Clash of the Two Titans in Geriatrics, Geriatrics. 2016; 1(4): 31. PMid:31022824 https: //doi.org/10.3390/geriatrics1040031

[9] Clare CS. Role of the nurse in stroke rehabilitation. Nurs Stand. 2018 Oct 1; 33(7): 59-66. PMid:30132306 https ://doi .org/10. 774 8/ns. 2018.e11194

[10] Quigley P. Focus on falls Prevention. American Nurse Today. 2105 10(7): 29-31.

[11] Alves VC, de Freitas WC, Ramos JS, et al. Actions of the fall prevention protocol: Mapping with the classification of nursing interventions. Rev Lat Am Enfermagem. 2017; 25: e2986. PMid:29267548 https://doi.org/10.1590/1518-8345.2394.2986

[12] Khedr EM, Elfetoh NA, Al Attar G, et al. Epidemiological study and risk factors of stroke in Assiut Governorate, Egypt: communitybased study. Neuroepidemiology. 2013; 40: 288-94. PMid:23486276 https://doi.org/10.1159/000346270

[13] World Health Organization. Fact sheet-fall, 2018. Available from: https://www. who.int/news-room/fact-sheets/deta il/falls

[14] Rockers PC, Røttingen JA, Shemilt I, et al. A quasi-experiment is an empirical interventional study used to estimate the causal im- 
pact of an intervention on target population without random assignment. Health Policy. 2015 Apr; 119(4): 511-21. PMid:25776033 https://doi.org/10.1016/j.healthpol.2014.10.006

[15] Morse JM, Morse RM, Tylko SJ. Development of a scale to identify the fall-prone patient. Can J Aging. 1989; 8: 366-7. https: //doi.org/10.1017/S0714980800008576

[16] Cho K, yu J, Rhee H. Risk factors related to faling in stroke patients: a cross-sectional study. J Phys Ther Sci. 2015; 27: 1751-3. PMid:26180313 https ://doi.org/10.1589/jpts.27.1751

[17] Geler KD. Fall Risk Evaluation in Stroke. Turk J Phys Med Rehab. 2015; 61: 296-7. https ://doi.org/10.5152/tftrd. 2015.002

[18] Mohsen MM, El-Mokadem NM, Abdullah SE. Effectiveness of physical rehabilitation on clinical outcomes of patients following stroke. Egypt Nurs J. 2017; 13: 200-10. https://doi .org/10.4103/20 90-6021. 200182

[19] Goh HT, Nadarajah M, Hamzah NB, et al. Falls and Fear of Falling After Stroke: A Case-Control Study. PM \& R. 2016.

[20] Said CM, Batchelor F, Shaw K, et al. Preparing patients at high risk of falls for discharge home after rehabilitation: Do we meet the guidelines? Geriatr Gerontol Int. 2016; 16: 570-576. PMid:25981682 https ://doi.org/10.1111/ggi.12511

[21] Czernuszenko A, Czonkowska A. Risk factors for falls in stroke patients during inpatient rehabilitation. Clin Rehabil. 2009; 23: 176-88. PMid:19164405 https ://doi.org/10.1177/02692155080988 94

[22] Tsur A, Segal Z. Falls in Stroke Patients: Risk Factors and Risk Management. IMAJ. 2010; 12(4): 216-9.

[23] Callis N. Falls prevention: Identification of predictive fall risk factors. Applied Nursing Research. 2016; 29: 53-58. PMid:26856489 https://doi.org/10.1016/j.apnr.2015.05.007

[24] Hanger HC, Wills KL, Wilkinson T. Classification of falls in stroke rehabilitation-not all falls are the same. Clin Rehabil. 2014; 28 :
183-95. PMid:23881335 https : //doi .org/10.1177/02692155 13496801

[25] Moncada LVV, Mire LG. Preventing fall in older persons. Am Fam Physician. 2017; 96(4): 240-247.

[26] Kulcu G. Fall Risk Evaluation in Stroke. Turk J Phys Med Rehab. 2015; 61: 296-7. https://doi .org/10.5152/tftrd.2015.002

[27] Cavalcante TF, Ferreira SM, Moreira RP, et al. Nursing interventions for the prevention of falls in patients with stroke. International Journal of Development Research. January 2018; 08(01): 18221-18225.

[28] Goto Y, Otaka Y, Suzuki K, et al. Incidence and circumstances of falls among community-dwelling ambulatory stroke survivors: A prospective study. Geriatr Gerontol Int. 2019; 19: 240-244. PMid:30623545 https://doi.org/10.1111/ggi.13594

[29] Schmid AA, Yaggi HK, Burrus N, et al. Circumstances and consequences of falls among people with chronic stroke. J Rehabil Res Dev. 2013; 1277-1286. PMid:24458967 https ://doi .org/10.1 682/JRRD. 2012.11.0215

[30] Schneider MA. The Importance of Educating Patients with Stroke about Vitamin D. J Neurosci Nurs. 2017 Dec; 49(6): 387-389. PMid:29117036 https://doi.org/10.1097/JNN.0000000000 000326

[31] Resnick B, Galik E, Boltz M, et al. Impact of Function Focused Care and Physical Activity on Falls in Assisted Living Residents. Can J Nurs Res. 2020; 52(1): 45-53. PMid:31225738 https: //doi.org/10.1177/0844562119856224

[32] Dean CM, Rissel C, Sherrington C, et al. Exercise intervention to prevent falls and enhance mobility in community dwellers after stroke: a randomised controlled trial. Sydney: NSW Ministry of Health; 2011.

[33] Divani AA, Vazquez G, Barrett AM, et al. Risk Factors Associated With Injury Attributable to Falling Among Elderly Population With History of Stroke. Stroke. 2009; 40: 3286-3292. PMid:19628798 https ://doi.org/10.1161/STROKEAHA.109.559195 